Карабущенко Н.Б., Стефанишина М.В.

Российский университет дружбы народов, г. Москва, Россия

E-mail: mar.stefanishina@mail.ru

\title{
ОСОБЕННОСТИ ПРЕОДОЛЕНИЯ СТРЕССА СТУДЕНТАМИ-ПСИХОЛОГАМИ
}

Karabushchenko N.B., Stefanishina M.V.

Friendship University of Russia (RUFP), Moscow, Russia

\section{PECULIARITIES OF OVERCOMING STRESS BY STUDENTS-PSYCHOLOGISTS}

Способность получать и перерабатывать информацию, готовность применять полученные навыки на практике, возможность быстро адаптироваться к изменяющейся социальной ситуации - условия успешной жизнедеятельности человека. Однако далеко не каждая личность способна выдерживать серьезные нагрузки и ей требуется квалифицированная психологическая помощь. Следовательно, подготовке практических психологов должно уделяться серьезное внимание. И в этой связи исследование стрессоустойчивости личности студентов-психологов приобретает особую актуальность, подчеркивающую значимость развития у них навыков владения собой в трудной ситуации, готовность контроля эмоций других людей, урегулирования конфликтных противоречий. Исследование проводилось на основе сравнения двух выборок студентов-психологов: 1 и 4 курсов на базе РУДН (Российского университета дружбы народов). Полученные результаты вскрыли интересные Факты: у старшекурсников уровень стресса выше, чем у первокурсников, что во многом обусловлено появлением новой социальной ситуации, определяемой, как выбор дальнейшей жизненной траектории (обучение, трудоустройство, смена семейного статуса). Использование копинг-стратегий в проблемных ситуациях имеет характерные черты в разные возрастные периоды: “Стратегическое планирование”, осмысление конкретных шагов для решения поставленных задач - характеризует четверокурсников, поддержка авторитетного взрослого, эмоциональные контакты со сверстниками важны для первокурсников. Студентов начальных курсов характеризует коллективистская направленность, готовность контролировать собственные эмоции и понимать чувства других людей. Старшекурсники ориентированы на индивидуальные цели, становясь при этом менее чувствительны к пониманию переживаний другого человека.

Таким образом, студенты первого и четвертого курсов отличаются различными способами реагирования на стрессовые ситуации. Первые более эмоциональны и оптимистичны, вторые - рациональны, зрело оценивают свои возможности и строят планы на будущее.

Ключевые слова: стресс, копинг, поведение, личность, студенты, общение, стратегии, жизненные трудности, трудные ситуации.

The ability to receive and process information, the willingness to apply the acquired skills in practice, the ability to quickly adapt to a changing social situation are the conditions for a person's successful life. However, not every person is capable of withstanding serious loads that's why he/she can be in need of qualified psychological help. Therefore, the preparation of practical psychologists should be under serious attention. In this regard, the study of the stress-resistance of the students-psychologists' personality acquires a special urgency, emphasizing the importance of developing their skills of owning themselves in difficult situations, the readiness to control other people emotions, and the resolution of conflict contradictions. The study was conducted on the basis of a comparison of two samples of 1 and 4 -year students-psychologists of RUDN-University (Peoples Friendship University of Russia). The results revealed interesting facts: undergraduates' level of stress is higher than that of freshmen, which is largely due to the emergence of a new social situation, defined as the choice of a further life trajectory (education, employment, and change of marital status). The use of coping strategies in problem situations has specific features in different age periods: "Strategic planning", the comprehension of concrete steps for solving the tasks posed - characterizes four-year students; support of an authoritative adult, emotional contacts with peers are important for first-year students. The collectivist orientation, the willingness to control one's own emotions and understand the feelings of other people characterizes the students of the first courses. Senior students are focused on individual goals, becoming less sensitive to understanding the experience of others.

Thus, students of the first and fourth courses differ in ways of responding to stressful situations. The former students are more emotional and optimistic, the latter students are rational, they maturely assess their capabilities and plans for the future.

Key words: stress, coping, behavior, personality, students, overstrain, communication, strategies, life difficulties, difficult situations.

Психологические исследования, посвященные изучению стресса, приобретают особую актуальность на современном этапе развития общества. Это обусловлено увеличением стрессогенных факторов: экономической и социально-политической нестабильностью, техногенными и экологическими угрозами, усиливающимися информационными потоками. Все это оказывает травмирующее воздействие на личность: эмоциональное напряжение, стресс, постравматические поведение.

Обратимся к основным психологическим подходам, отражающим проблему изучения стресса. По мнению В.А. Бодрова, источником 
стресса является информация из внешней среды о протекающем или возможном действии угрожающих событий, либо подсознательная информация о тяжелых пережитых когда-то событиях. Сама информация, как источник будет запускать и определять степень угрозы стрессогенного события, а также необходимые элементы регуляции процесса выхода из критической ситуации [3]. Вследствие этого, любой стресс, касающийся личности и ее деятельности в своем фундаменте, имеет «информационный характер» [3].

Конфликты на работе, сложные рабочие условия будут вызывать «производственный» стресс, определяемый самой деятельностью. Так, говорят об «авиационном», «спортивном» стрессах и др., испытываемых человеком в осуществляемой им профессиональной деятельности [7]. Перегрузка в интеллектуальной сфере без требуемого отдыха может спровоцировать «психическое» перенапряжение, сопровождающееся ухудшением психической деятельности. Трудные ситуации не изменяют самочувствия человека напрямую, их влияние опосредовано всей совокупностью мотивационно-личностных особенностей, отношением к сложившейся ситуации, опытом преодоления - всеми факторами, определяющими индивидуальные различия в реагировании на стресс.

Проблема стресса зарубежными и российскими исследователями изучается уже давно. Начало научного подхода в зарубежных исследованиях стресса положили У. Кеннон, Г. Селье, которые рассматривали стресс с психофизиологической точки зрения, со стороны физиологических реакций организма на стресс (учащение сердцебиения). Теории Р. Лазаруса и С. Фолкмана основываются на когнитивных основаниях, акцентируя внимание на изучении «повседневного стресса». А. Биллингс и Р. Моос [11] выделяют такие способы копинг поведения, как оценка ситуации, вмешательство в ситуацию и избегание [11]. А. Хаммер и М. Зейднер [15] определяют копинг поведение с точки зрения ресурсов, которые необходимы для преодоления сложных ситуаций. К ним они относят сферы представления и познания, сферу чувств, сферу отношений с другими людьми, сферу духовности и физического бытия [15]. Немецкий исследователь Х. Томе [13] выделил среди прочих основных реакций на стресс приспособление к особенностям и потребностям других людей, отождествление с целями и судьбами других, настроенность на то, чтобы не упустить свой шанс и др. П. Виталиано [14] изучал преодолевающее поведение относительно различных групп: профессиональных, возрастных, социальных. Вместе с проблемно-ориентированным способом преодоления он выделил способы эмоционально-ориентированного копинга, это: обвинение, критика, сожаления, поучения человеком самого себя, поведение, как будто ничего не произошло, надежда на чудо. Н. Хаан считает, что в достаточно спокойном, уравновешенном состоянии и при незначительном стрессе стратегии и тактики преодолевающего поведения отличаются своей нацеленностью и гибкостью, т. е. человек использует копинги, когда имеет возможность действовать обдуманно. А в том случае, если нужно действовать быстро и времени нет на размышление (либо отсутствуют варианты выхода из ситуации), то прибегает к защитному поведению[12].

Концепция копинга многогранно в нашей стране стала рассматриваться с 90-х годов. Вопросами изучения преодоления стресса занимаются различные ученые: Л.Г. Дикая, А.Б. Леонова, Л.И. Анцыферова, В.А. Бодров, Л.А. Китаев-Смык, Т.Л. Крюкова, М.В. Сапоровская, Н.Е Водопьянова, Ю.В. Щербатых, К.С. Абульханова-Славская, Л.А. Головей, О.Ю. Стрижицкая, С.К. Нартова-Бочавер, М.А. Падун, А.Н. Зелянина, Н.В. Тарабрина, Г.Б. Монина и др.

Л.И. Анцыферова рассматривает проблему копинга, обращая внимание на взаимосвязь личности и окружающего мира, влияния субъективных характеристик личности на выбор преодолевающих стратегий, рассмотрение стрессовых событий в зависимости от предшествующих им ситуаций и состояний человека [2]. По мнению К.С. Абульхановой, человек сам является субъектом своего поведения либо активно создающим его, либо пассивным исполнителем своего способа поведения [1].

Копинг поведение отечественными исследователями рассматривается с точки зрения детерминирования ряда факторов: личностных, ситуационных, экологических (социокультурных) и регулятивных. Важными направления- 
ми исследований в данной области являются: индивидуальные ресурсы, способствующие преодолению стресса (Е.А. Сергиенко), преодолевающее поведение в ситуациях травматического стресса (И.С. Хажуев, Н.В. Тарабрина), среда дома как важная сфера жизнедеятельности человека (С. К. Нартова-Бочавер), преодолевающее поведение в семье (Сапоровская, 2002 , 2007; Крюкова, 2004), копинг поведение в юношеском возрасте (Замышляева, 2006) и др.

В работе психолога проблема преодоления стресса одна из ключевых. Это связано как со способностью самостоятельно находить оптимальные приемы и стратегии выхода из травмирующих ситуаций, так и с готовность работать со стрессом в процессе индивидуального и группового консультирования. Следовательно, подготовка психологов-практиков в вузе должна включать обучающие мероприятия, направленные на освоение техник преодолевающего поведения. Проведенное нами исследование было направлено на изучение особенностей реагирования на стресс и специфики выбора копингстратегий студентами-психологами.

Исследование проводилось в 2017-2018 г.г. на базе филологического факультета кафедры психологии и педагогики РУДН. В исследовании приняли участие 80 человек: 1-го (40 человек) и 4-го (40 человек) курсов по направлению «Психология». Возраст студентов составил 18-23 года. Были использованы следующие методики:«Шкала психологического стресca PSM 25» в адаптации Н.Е. Водопьяновой, «Шкала оптимизма и активности AOS» в адаптации Н.Е. Водопьяновой, опросник «Проактивноесовладающее поведение» (PCI), Опросник эмоционального интеллекта «ЭмИн» Д.В. Люсина. Статистическая обработка данных осуществлялась с помощью программы SPSS 21, при помощи непараметрического критерия U Мана-Уитни.

Результаты эмпирического исследования по тесту «Шкала оптимизма и активности AOS» показали следующее: оптимизм у студентов 1-го курса существенно выше, чем у 4-го курса $(\mathrm{U}=593,5 ; \mathrm{P}=0,046)$ (рис. 1).

Статистически значимых различий по шкале активность не выявлено $(\mathrm{U}=626 ; \mathrm{P}=0,093)$, но наблюдается тенденция к снижению уровня активности к 4-ку курсу.
Повышенный уровень оптимизма и активности у студентов 1-го курса по сравнению с 4-ым объясняется возрастными особенностями и задачами развития на данном возрастном этапе. Для первокурсников характерно: оптимистичный взгляд в будущее, уверенность в себе и в своих поступках. Студенты старших курсов, погружаясь в профессию, обретая практический опыт, отличаются более зрелым взглядом на происходящие события, оценивают риски и готовы к преодолению возникающих проблем. Однако уровень активности четверокурсников снижается, что обусловлено подготовкой к новому этапу их профессиональной деятельности. На данном этапе нивелируется необходимость налаживать контакты в студенческой среде, адаптироваться к условиям образовательного учреждения, решать повседневные учебные задачи, что крайне актуально для только что поступившего в вуз студента.

Сравнительный анализ результатов, полученный на базе опросника«Шкала психологического стресса PSM 25», не выявилстатистически значимых различий в уровне стресса студентов двух курсов. Однако на уровне тенденций старшекурсники показывают повышенный уровень стресса $(\mathrm{U}=748,5 ; \mathrm{P}=0,62)$ (рис. 2$)$, что обусловлено переживанием ситуации выбора: продолжить ли образование, работать ли по вы-

\section{Средний ранг}

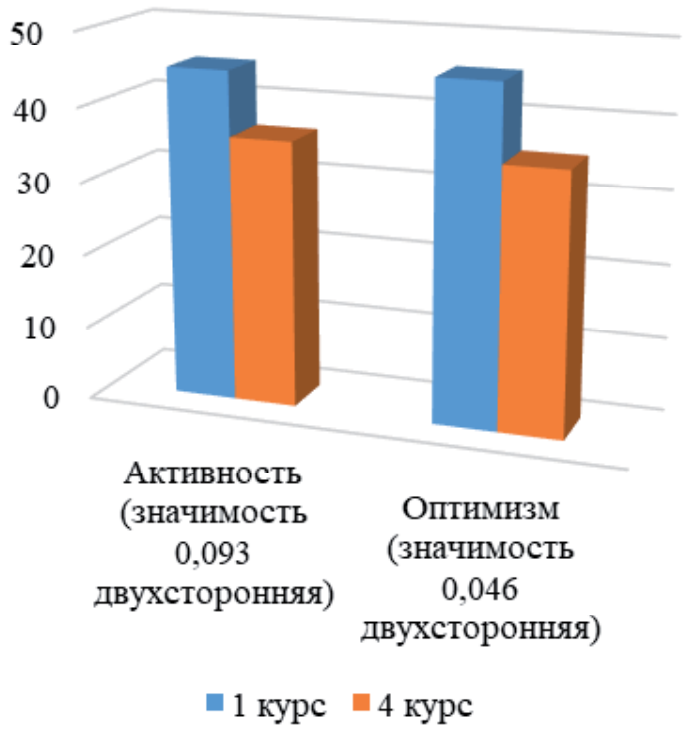

Рисунок 1 - Особенности проявления активности и оптимизма у студентов-психологов 


\section{Психология}

бранной профессии, выбор рабочей стези в рамках полученной профессии. Следует отметить, что среди студентов-психологов подавляющее большинство девушек, которые вплотную подходят к решению личных вопросов: созданию семьи, рождению детей. Сложности во взаимоотношениях с противоположным полом также способствуют переживанию стрессовых ситуаций. Также не следует забывать о подготовке к выпускным экзаменам и защите бакалаврской

\section{Средний ранг}

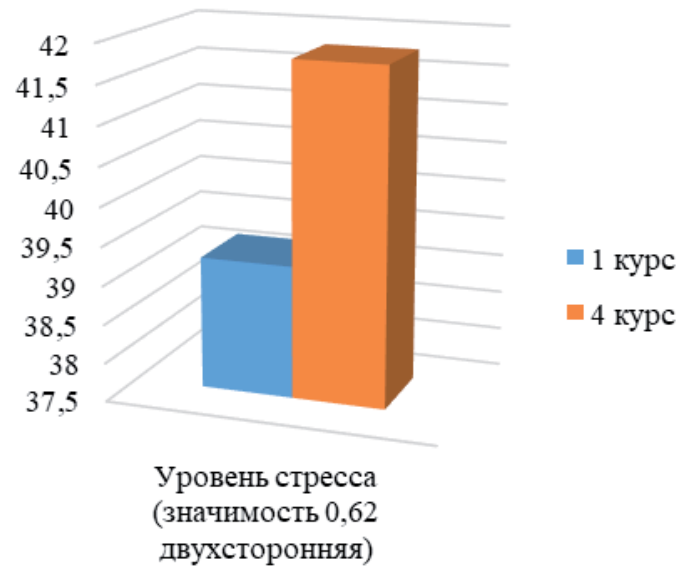

Рисунок 2 - Уровень стресса у студентов-психологов диссертации, что повышает уровень тревожности и нервно-психического напряжения.

На основе полученных эмпирических результатов по методике «Проактивноесовладающее поведение» (PCI) не было выявлено статистически значимых различий (рис 3 ). Но на уровне тенденций были прослежены различия. По шкалам «Проактивноепреодоление» и «Поиск эмоциональной поддержки»показатели у студентов 1-го курса выше, чем у старшекурсников.

Предпочтение в выбореданных стратегий студентами начальных курсов обусловлено активизацией процесса целеполагания, направленного на конкретизацию учебных задач и решение текущих вопросов. На начальных этапах обучение для студентов значимым становится формирование навыков саморегуляциии готовности к личностному росту. При этом эмоциональные контакты играют важную роль в жизни первокурсников. Межличностное общение выполняет функцию адаптационного механизма в новой среде, дистрессора в трудных ситуациях, источника знаний об эмоциональных проявлениях личности. По мнению Нартовой-Бочавер, молодым людям юношеского возраста также характерно эмоциональное разрешение проблем [9].

\section{Средний ранг}

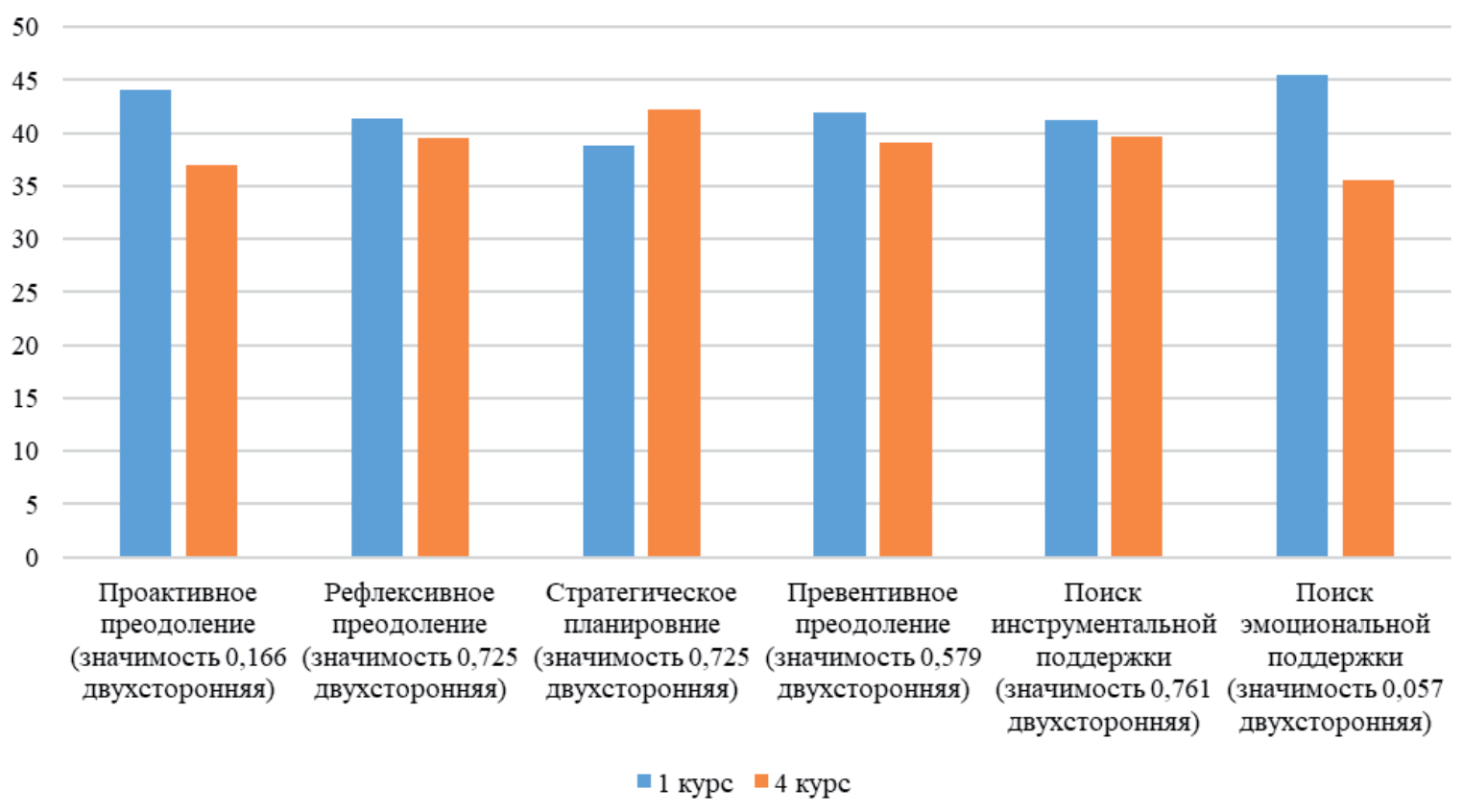

Рисунок 3 - Предпочтения в выборе копинг-стратегий студентами-психологами 
Стратегическое планирование как стратегия преодоления студентами 4-го курса использоваться чаще, чем первокурсниками. Выпускники бакалавриата способны ставить перед собой масштабные задачи, как в личностном, так и в профессиональном плане. Для них характерно построение древа целей, отражающего дальнейшую их жизнь и те планы, которые будут реализованы в ближней и дальней перспективе.

По шкалам «Рефлексивное преодоление», «Превентивное преодоление», «Поиск инструментальной поддержки» на уровне тенденций результаты первокурсников оказались выше, чем у четверокурсников. Подобная тенденция во многом определяется тем, что на начальном этапе обучения студент склонен к размышлениям по поводу способов преодоления сложных ситуаций, пытается найти способы нейтрализации негативных последствий стрессовых событий, чаще обращается за помощью и советом к авторитетным людям.

В ходе сравнительного анализа результатов исследования по методике Опросник эмоционального интеллекта «ЭмИн» были получены интересные данные (рис. 4).

Различия в уровне общего эмоционального интеллекта (ОЭИ) статистически значимы $(\mathrm{U}=454,5 ; \mathrm{P}=0,001)$. Таким образом, уровень ЭИ у студентов четвертого курса ниже, чем у первокурсников.
Студенты начальных курсов нуждаются в эмоциональном контакте, находясь в ситуации адаптации к новым учебным условиям, они ориентированы на расширение социальных связей, поиск друзей и спутников жизни, следовательно, освоение навыков эмоционального взаимодействия выходит на первый план. Таким образом, МЭИ (межличностный ЭИ) на статистически значимом уровне выше у первокурсников, чем у студентов 4 курса $(U=510$; $\mathrm{P}=0,005)$. Готовность к лучшему пониманию эмоций другого человека, коллективистская направленность студентов начальных курсов активизирует способность понимания $(\mathrm{U}=544$; $\mathrm{P}=0,014)$ и управления чужими эмоциями $(\mathrm{U}=442 ; \mathrm{P}=0,001)$. Они учатся контролировать проявление собственной экспрессии $(\mathrm{U}=468,5$; $\mathrm{P}=0,001)$, с целью налаживания контактов не только с однокурсниками, но и с профессорскопреподавательским составом университета.

Попадая в новые учебные и бытовые условия, а многие студенты проживают в общежитиях, первокурсники осуществляют поиск оптимальных стратегий поведения, вырабатывают способы реагирования в конфликте, подбирают приемлемые для себя стратегии совладания со стрессом. Все это способствует обогащению эмоциональной сферы личности студентов начальных курсов. Эмоциональная подвижность свидетельствует о более высоком уровне внутриличностного ЭИ $(\mathrm{U}=534,5 ; \mathrm{P}=0,011)$.

Средний ранг

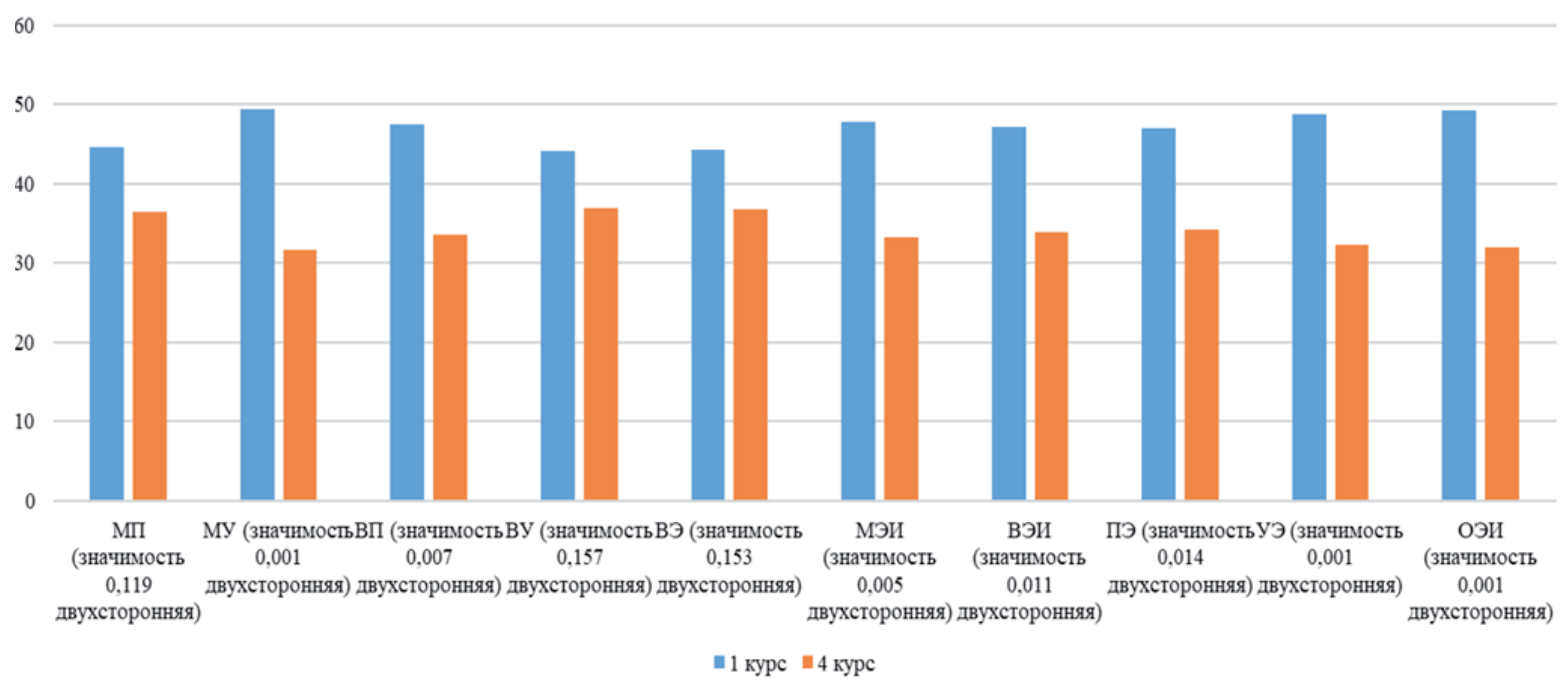

Рисунок 4 - Особенности в проявлениях эмоционального интеллекта студентами-психологами 


\section{Психология}

Первокурсники лучше распознают свои эмоции, понимают причины их возникновения, способны к словесному их выражению (ВП - понимание своих эмоций $(\mathrm{U}=522,5 ; \mathrm{P}=0,007))$, чем четверокурсники, что обусловлено меньшей лабильностью эмоциональной сферы в более старшем возрасте.

Для старшекурсников приоритетным становится общение в группах единомышленников. Многие, особенно девушки, ориентированы на создание семьи. Широкие социальные контакты уходят на второй план. Следовательно, стратегии поведения, выработанные на первых курсах, становятся устойчивыми и стабильно используются личностью, как наиболее приемлемые.

\section{Выводы}

Проблема изучения стресса и реагирования личности в трудных ситуациях является актуальной для современного общества. Новые социальные и технологические вызовы стимулирую личность к поиску способов адаптации к новым условиям. Молодое поколение, оказавшись «в эпицентре событий», должно не только совершенствовать свою профессиональную и информационную грамотность, но и психологическую компетентность, с целью преодоления трудностей, возникающих на жизненном пути.

Проведенное эмпирическое исследование на студентах-психологах, представляющих 1-й и 4-й курсы, вскрыло интересные факты. У старшекурсников уровень стресса выше, чем у студентов младшего курса, что обусловлено новой социальной ситуацией, в которую попадают выпускники: это и поиск места работы, дальнейшего профессионального самоопределения, это и новый социальный статус, это и поиск партнера для совместной жизни.

Следовательно, использование копингстратегий в ситуациях стресса у студентов разных курсов отличается либо преобладанием эмоционального, либо рационального аспектов. Старшекурсники ориентированы на стратегическое планирование, первокурсники чаще обращаются за советом к авторитетным взрослым, склонны к анализу собственных переживаний в трудных жизненных ситуациях. При этом последние оптимистично настроены, т. к. для них наступил новый этап в жизни - студенческий период, они строят планы на будущее, представляют себя в профессии. На данном этапе студенты эмоционально более открыты, учатся понимать и контролировать свои и чужие эмоции, принимают участие в коллективных мероприятиях, обретают новых друзей. Студентывыпускники более сдержаны и действуют рационально, что не всегда продуктивно влияет на развитие эмоционального интеллекта, т. к. появляется меньшая гибкость в эмоциональном реагировании и контроле экспрессии. Однако данный факт обусловлен социальной ситуацией, в которой оказывается четверокурсник, стоящей перед выбором дальнейшего пути.

«Развитый эмоциональный интеллект, способность понимать свои и чужие эмоции, умение управлять эмоциональными состояниями других и своими собственными - важнейший показатель элитности личности»[6], ее эмоциональной зрелости и профессионального становления.

16.11 .2017

Список литературы:

1. Абульханова-Славская, К.А. Стратегия жизни / К.А. Абульханова-Славская. - М.: Мысль, 1991.

2. Анцыферова, Л.И. Личность в трудных жизненныхусловиях: переосмысление, преобразование ситуаций ипсихологическая защита / Л.И. Анцыферова // Психологический журнал. - 1994. - Т. 15. - №1 - С. 3-18.

3. Бодров, В.А. Информационный стресс / В.А. Бодров. - М.: ПЕР СЭ, 2000. - 352 с.

4. Бодров, В.А. Психологический стресс: развитие и преодоление / В.А. Бодров. - М.: ПЕР СЭ, 2006.

5. Ениколопов, С.Н. Психологические последствия терроризма и роль СМИ в процессе их фомирования / С.Н. Ениколопов, А.А. Мкртчян // Национальный психологический журнал. - 2010. - №2(4). - С. 41-46.

6. Карабущенко, Н.Б. Психология профессиональных элит в вузе / Н.Б. Карабущенко. - СПб.: Издательский Дом «Алеф-Пресс», 2016. - C. 238 .

7. Климов, Е.А. Материалы Международной научно-практической конференции «Психология развития человека как субъекта труда. Развитие творческого наследия Е.А. Климова» / Е.А. Климов; под ред. Ю.П. Зинченко, А.Б. Леоновой, О.Г. Носковой. - Москва, 2016.

8. Малкина-Пых, И.Г. Возрастные кризисы. Справочник практического психолога / И.Г. Малкина-Пых. - Изд-во: Эксмо, 2004. $896 \mathrm{c}$.

9. Нартова-Бочавер, С.К. Значимые события в жизни современных подростков / С.К. Нартова-Бочавер, А.А. Бородина // Актуальные проблемы современного детства. - М., 1996. - С. 63-66. 
10. Хухлаева, О.В. Психология развития: молодость, зрелость, старость: учеб. пособие для студ. высш. учеб. заведений / О.В. Хухлаева. - М.: Издательский центр «Академия», 2002. - 208 с.

11. Billings, A.G. Coping, stress, and social resources amongadults with unipolar depression / A.G. Billings, R.H. Moos // J. Pers and Soc. Psychol. - 1984. - T. 46. - C. 877-891.

12. Haan, N. Coping and defending. Process of self-environment organization / N. Haan. - NewYork: AcademicPress, 1977.

13. Thomae, H. Das Individuum und seine Welt / H. Thomae. - Goettingen, Toronto, Zuerich, 1988.

14. Coping Profiles Associated With Psychiatric, Physical Health, Work, and Family Problems / Vitaliano P.Р. [и др.] // Health Psychol. 1990. - T. 9(3). - C. 348-376.

15. Zeidner, M. Life events and coping resources as predictors of stress symptome in adolescents / M. Zeidner, A. Hammer // Pers. Individ. Diff. - 1990. - T. 11. - №7. - C. 693-703.

\section{References:}

1. Abul'hanova-Slavskaya K.A. Strategiya zhizni [Strategy of life]. M.: Mysl', 1991.

2. Ancyferova L.I. Lichnost' v trudnyh zhiznennyhusloviyah: pereosmyslenie, preobrazovanie situacij ipsihologicheskaya zashchita. Psihologicheskij zhurnal [Psychological journal], 1994, vol. 15, no. 1, pp. 3-18.

3. Bodrov V.A. Informacionnyj stress [Information stress]. M.: PER SEH, 2000, 352 p.

4. Bodrov V.A. Psihologicheskij stress: razvitie i preodolenie [Psychological stress: development and overcoming]. M.: PER SEH, 2006.

5. Enikolopov S.N., Mkrtchyan A.A. Psihologicheskie posledstviya terrorizma i rol' SMI v processe ih fomirovaniya. Nacional'nyj psihologicheskij zhurnal [National Psychological Journal], 2010, no. 2(4), pp. 41-46.

6. Karabushchenko N.B. Psihologiya professional'nyh ehlit v vuze [Psychology of professional elites in the universit]. SPb.: Izdatel'skij Dom «Alef-Press», 2016, p. 238.

7. Klimov E.A., eds. YU.P. Zinchenko, A.B. Leonova, O.G. Noskova Materialy Mezhdunarodnoj nauchno-prakticheskoj konferencii «Psihologiya razvitiya cheloveka kak sub»ekta truda. Razvitie tvorcheskogo naslediya E.A. Klimova» [Materials of the International Scientific and Practical Conference «Psychology of Human Development as a Subject of Labor. Development of the creative heritage of E.A. Klimova»]. Moskva, 2016.

8. Malkina-Pyh I.G. Vozrastnye krizisy. Spravochnik prakticheskogo psihologa [Age crises. Handbook of practical psychologist]. Izd-vo: EHksmo, 2004, 896 p.

9. Haptova-Bochaver S.K., Borodina A.A. Znachimye sobytiya v zhizni sovremennyh podrostkov. Aktual'nye problemy sovremennogo detstva [Actual Problems of Modern Childhood], M., 1996, pp. 63-66.

10. Huhlaeva O.V. Psihologiya razvitiya: molodost', zrelost', starost': ucheb. posobie dlya stud. vyssh. ucheb. zavedenij [Psychology of growth: youth, maturity, old age: Textbook for university students]. M.: Izdatel'skij centr «Akademiya», 2002, 208 p.

11. Billings A.G., Moos R.H. Coping, stress, and social resources amongadults with unipolar depression. J. Pers and Soc. Psychol, 1984, vol. 46, pp. 877-891.

12. Haan N. Coping and defending. Process of self-environment organization. NewYork: AcademicPress, 1977.

13. Thomae H. Das Individuum und seine Welt. Goettingen, Toronto, Zuerich, 1988.

14. Vitaliano P.P. et al. Coping Profiles Associated With Psychiatric, Physical Health, Work, and Family Problems. Health Psychol, 1990, vol. 9(3), pp. 348-376.

15. Zeidner M., Hammer A. Life events and coping resources as predictors of stress symptome in adolescents. Pers. Individ. Diff., 1990, vol. 11, no. 7 , pp. 693-703.

\section{Сведения об авторах:}

Карабущенко Наталья Борисовна, заведующий кафедрой психологии и педагогики Российского университета дружбы народов, доктор психологических наук, профессор E-mail: n_karabushenko@inbox.ru

Стефанишина Марина Владимировна, магистрант 2 курса кафедры психологии и педагогики по направлению «Психологическое консультирование» Российского университета дружбы народов

117198, г. Москва, ул. Миклухо-Маклая, 10а 